\title{
NÃO SEJA BURRO!: preconceito como a chave para o sucesso
}

\section{DON'T BE STUPID!: prejudice as key to}

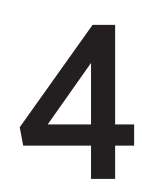

success

\section{SANTOS, Larissa Bueno}

Mestranda no Programa de Pós-graduação em Linguística e Língua Portuguesa da Faculdade de

Ciências e Letras - Araraquara (UNESP) - bolsista CNPq

E-mail: labueno.lbs@gmail.com

\section{MENDONÇA, Marina Célia}

Doutora em Linguística pela Universidade Estadual de Campinas - Unicamp

Docente do Departamento de Linguística da Faculdade de Ciências e Letras - Araraquara (UNESP)

Pós-doutoranda no IEL/Unicamp.

E-mail: marina.mendonca@unesp.br

\section{RESUMO:}

Este artigo busca analisar, à luz de teorias sociolinguísticas, o primeiro vídeo da série online Não seja burro!, de Marcela Tavares, veiculada no YouTube e no Facebook. O primeiro vídeo dessa série teve grande repercussão nessas redes e contava com 1.470.952 visualizações no YouTube em julho de 2017. A série, composta, até a data de elaboração deste artigo, por 14 vídeos, propõe ensinar a escrever e a falar "corretamente" a língua portuguesa, de acordo com uma gramática normativa do português que não é explicitada, seguindo as regras da autointitulada professora Marcela Tavares, a qual institui formas "corretas" e "erradas" de se expressar. Como atestado por Santos (2017), os enunciados de Tavares são perpassados por um discurso purista sobre a linguagem, o qual despreza as variedades linguísticas, tomando-as como erradas, instituindo o que chamamos de preconceito linguístico. Neste artigo, pesquisa ampliada de Trabalho de Conclusão de Curso (SANTOS, 2017), com base estudos em Sociolinguística, buscamos, primeiramente, discutir alguns conceitos teóricos e, a seguir, apresentar a análise de alguns comentários de Marcela Tavares presentes no primeiro vídeo de sua série online, explicitando a coerência dessas ocorrências condenadas, tendo em vista o sistema da língua portuguesa, e a incoerência de Tavares ao julgá-las

Palavras-chave: sociolinguística; preconceito linguístico; letramento 


\section{ABSTRACT:}

This paper wishes to analyze, in light of sociolinguistic theories, the first video of the online series "Don't be stupid!", by Marcela Tavares, available on YouTube and Facebook. The first video in the series had a big repercussion on these websites and by July 2017 they had already $1,407,952$ views on YouTube. The series, which until this paper was written had 14 videos, aims to teach how to write and speak "proper" Portuguese, according to a non-explicit normative grammar, following the rules of the self-proclaimed teacher Marcela Tavares, who sets "wrong" and "right" ways to express yourself. As said by Santos (2017), Tavares' speech is affected by a purist approach on language, one that despises linguistic varieties, seeing them as wrong, creating what we call linguistic prejudice. In this paper, a broadened research of an endof-term dissertation (SANTOS, 2017), based on sociolinguistic studies we aim, primarily, to discuss theoretical concepts and then present an analysis of some comments made by Marcela Tavares on the first video of her online series, explaining the coherence behind these events condemned by her, from the point of view of how the Portuguese language functions, and Tavares' incoherence in judging them.

Key-words: sociolinguistics; linguistic prejudice; literacy

\section{INTRODUÇÃO}

[...] a língua é uma entidade social em constante transformação por nós que a inventamos e reinventamos todos os dias" - Marcos Bagno em entrevista (A língua como poder) à UNE para sua $9^{\text {a }}$ Bienal.

[...] qualquer língua é sempre heterogênea, ou seja, constituída por um conjunto de variedades (por um conjunto de normas). Não há, como muitas vezes imagina o senso comum, a língua, de um lado, e de outro, as variedades. A língua é em si o conjunto das variedades. Ou seja, estas não são deturpações, corrupções, degradações da língua, mas são a própria língua: é o conjunto de variedades (de normas) que constitui a língua (FARACO, 2008, p. 73-74).

A heterogeneidade linguística é um fato. Com o passar do tempo, as línguas mudam, como as sociedades mudam, e são essas heterogeneidades sociais e linguísticas, podendo influenciar-se 
mutuamente, que ocasionam as mudanças. Apesar da diversidade, todas as línguas possuem um núcleo comum, uma sistematicidade que, da ortografia à sintaxe, gerencia discursiva/textualmente em sintagmas todas as possibilidades que tal língua comporta, é um cálculo de produção de sentido (NEVES, 2018). À essa sistematicidade damos o nome de gramática. Neutra, pois é um sistema, ela minimiza variações. Toda língua tem gramática, mas a gramática não é a língua, como aponta Bagno (1999).

Alíngua se configura como a realização de todas as possibilidades que sua gramática comporta. Assim, todas as variedades linguísticas têm gramática e possuem regras de funcionamento. Contudo, confundidas, língua e gramática são tomadas como sendo uma só. Desse modo, as possibilidades de realização do sistema linguístico que aparecem em instrumentos linguísticos, como dicionários, gramáticas, dentre outros, são tidas como corretas e únicas, havendo a estigmatização das demais. Em sua maioria, esses instrumentos não levam em consideração os usos reais que os falantes fazem da língua.

Segundo Bagno (1999, p. 9) "Nossa tarefa mais urgenteé desfazer essa confusão", pois, do ponto de vista linguístico, as variedades são todas corretas e não há uma melhor do que outra, há diferenças. As valorações das formas linguísticas são construídas no meio social. Assim, algumas variedades, por serem identificadas a grupos sociais de baixo prestígio, são estigmatizadas. Contemplam, assim, além de formas linguísticas, valores socioculturais. A esse julgamento negativo damos o nome de preconceito linguístico.

Veiculado por um discurso purista sobre a linguagem, que se funda no conservadorismo extremo e na discriminação social, econômica e cultural contra aqueles que não seguem os padrões impostos e tidos como corretos das classes/dos grupos dominantes, o preconceito linguístico aparece intimamente relacionado ao mito do "déficit linguístico e cultural", o qual determina que as classes menos privilegiadas socioeconomicamente assim o são devido às suas próprias características, intrínsecas e orgânicas. Essa concepção é errônea, uma vez que o domínio das variedades prestigiadas depende, em grande parte, do acesso à escolarização.

Esse discurso do preconceito se fixa nas instituições escolares, onde o aluno aparece como responsável por seu "fracasso escolar", uma vez que é tido como "incompetente" e "carente" devido à sua 
origem social. A escola julga as variedades linguísticas dos alunos, impondo aquela que ela considera "correta" e boa" e segrega aqueles que não utilizam a variedade exigida, propagando as relações sociais desiguais. Soares (1986), já na década de 1980, destaca ideologias sobre a linguagem que estavam presentes nas escolas brasileiras, entre elas uma é especialmente relevante para essa discussão que fazemos aqui: a das "deficiências culturais", segundo a qual as classes populares teriam uma carência cultural (relacionada à afetividade, capacidade cognitiva e linguística) que as incapacitaria para o sucesso escolar

Já neste momento, no Brasil, temos estudos sobre letramentos e alfabetização que, apesar de enfoques e metodologias diferentes das utilizadas pela Teoria da Variação e Mudança, também apontam para a questão da forma como a identidade do sujeito social se constrói em função de sua relação com a linguagem (neste caso, a escrita).

É essa relação entre identidade, linguagem e preconceito que investigamos neste artigo, já que ela se faz presente no discurso dos vídeos da comediante Marcela Tavares. Vídeos que, enquanto mídias sociais, são de fácil compartilhamento e propagação, fazendo com que o preconceito linguístico e social ganhe ainda mais força.

Em nossa análise, selecionamos o primeiro vídeo da série Não seja burro!, lançado no YouTube em 11 de janeiro de 2016. Nosso estudo tem como base perspectivas da sociolinguística (LABOV, 2008; FARACO, 2008; BAGNO, 1999; WEINREICH, LABOV, HERZOG, 2006; LEITE, 2008) e dos Novos Estudos do Letramento (STREET, 2006).

\section{PRECONCEITO LINGUÍSTICO, ORALIDADE E ESCRITA}

A Sociolinguística é o ramo da Linguística que investiga as relações entre língua e sociedade buscando verificar como fatores sociais, econômicos, culturais, dentre outros, influenciam aspectos linguísticos. Autor de base da sociolinguística variacionista, Labov (2008) propõe que a língua seja estudada a partir de seu uso real e cotidiano, isto é, dentro do contexto social de uma determinada comunidade de fala. Para o linguista estadunidense, é fundamental estabelecer as relações existentes entre fatores linguísticos e extralinguísticos, presentes no meio social. Assim, fatores como gênero, classe social, escolaridade, idade etc. estão intimamente ligados à presença ou à ausência de determinados traços linguísticos.

A abordagem laboviana considera que todas as línguas naturais são heterogêneas, "resultado natural de fatores linguísticos 
fundamentais" (ibid., p. 238), podendo variar em diversos níveis linguísticos: fonético, morfológico, sintático, semântico, pragmático, lexical etc., assim como de acordo com fatores externos à língua: o tempo, o registro, a situação, a camada social e a região geográfica. Weinreich, Labov e Herzog (2006) afirmam que a heterogeneidade é constitutiva da língua e fundamental para que ela funcione. Além disso, acrescentam que todo falante é capaz de compreender essa heterogeneidade. Como aponta Beline (2008), a heterogeneidade na língua pode se transpor para a sociedade e vice-versa.

É preciso destacar que as mudanças e variações linguísticas não ocorrem repentinamente. Antecipando a mudança, estão as variações. Elas se caracterizam como processos linguísticos em que variantes de um mesmo traço convivem até que o novo se sobreponha ao antigo. Normalmente, esses processos se iniciam na fala de grupos menos privilegiados socialmente, estendendo-se à fala de grupos mais privilegiados. Então, gradativamente, a variação chega aos falares ditos "formais" e se propaga para a escrita. É também na fala de gerações mais jovens que tais processos tendem a começar (LABOV, 2008).

Destacamos que não são todos os elementos em variação que geram mudanças na língua. Alguns traços em variação assim permanecem, sem que um se sobreponha ao outro. Por isso, toda mudança linguística pressupõe variação, mas nem toda variação pressupõe mudança (WENREICH; LABOV; HERZOG, 2006).

As variedades linguísticas estão presentes nas comunidades de prática, "agregado de pessoas que partilham experiências coletivas no trabalho, nas igrejas, nas escolas, nos sindicatos e associações, no lazer, no cotidiano da rua e do bairro etc." (FARACO, 2008, p. 40) a que pertence o falante da língua. $E$, já que um mesmo falante se expressa por diversas variedades, configura-se como "um camaleão linguístico", segundo Faraco (2008).

Observamos que o traço inovador em variação, tendo surgido em comunidades de prática específicas, carrega características do grupo em que se originou, sendo valorado positiva ou negativamente. À medida que o processo de mudança avança, as valorações que circundam o traço inovador se intensificam e ele pode se tornar uma marca social, isto é, caracterizar determinado grupo. Em geral, quando o traço é proveniente de grupos menos privilegiados sócio-culturaleconomicamente, ele é valorado negativamente pelos falantes de 
grupos sociais mais favorecidos e contribui para formar estereótipos.

É por isso que, segundo Britto (2004, p. 153), "A diferença [...] não está no quanto uma palavra dita é diferente da forma modelar, está no quanto ela é identificada ou não com a fala dos grupos sociais menos favorecidos, o quanto está legitimada" e, segundo Labov (2008, p. 366): "Se o grupo for excluído da corrente dominante da sociedade, ou se seu prestígio diminuir, a forma linguística ou regra será estigmatizada, corrigida e até mesmo extinta".

Assim, algumas variedades e/ou traços inovadores são estigmatizados(as) devido ao cenário sociocultural em que se inserem. Segundo Guy e Zilles (2006, p. 42),

Uma das características mais importantes das línguas humanas e mais relevantes à questão do ensino da língua materna é a diversidade linguística. Este é um ponto básico nas pesquisas e teorias sociolinguísticas e, em princípio, não precisamos de nenhuma pesquisa acadêmica formal para reparar na existência desta diversidade. Ela é evidente pela experiência de todo mundo; entretanto, em muitas sociedades, como é o caso da sociedade brasileira, a representação sociocultural da língua de certo modo oblitera essa percepção, fazendo crer que a língua de verdade não varia - ou, numa exacerbação idealizada, faz crer que a língua não deveria variar.

Do ponto de vista linguístico, nenhuma variedade é melhor do que outra, elas são, simplesmente, diferentes, mas, tomando a língua como invariável e homogênea, e impondo uma única variedade linguística como correta, perpetua-se um discurso purista sobre a linguagem em que apenas uma forma linguística deve prevalecer, sendo ela chamada de correta e as demais de erradas, de deturpações.

Ao defender a existência de uma única língua correta, tomando língua e variedades como coisas distintas, quando, na verdade, a língua é o conjunto de suas variedades, o discurso purista sobre a linguagem impõe e dissemina uma forma linguística baseada num padrão normativo da língua que não é efetivamente empregado pelos falantes. A norma-padrão, como é conhecida, não está na boca de ninguém, como diz Bagno (1999).

A normatividade remonta à formação dos Estados Nacionais, quando, a fim de estabelecer uma língua oficial comum e homogênea 
"para atenuar a diversidade lingüística regional e social herdada da experiência feudal" (FARACO, 2008, p. 74) elabora-se uma língua padrão, neutra, "trabalho de normalização dos produtos dos habitus lingüísticos" (BOURDIEU, 1996, p. 34) consagrados em língua escrita, pois a forma de língua reconhecida como correta é aquela identificada à escrita e não à fala (ibid., p. 35). Assim, a norma-padrão é meramente um código impessoal.

Imposta pelo sistema escolar, veiculada por gramáticas e dicionários, a norma-padrão é prescrita como única forma legítima em detrimento das variedades linguísticas, desvalorizando-as, rotulando-as de "dialetos", "gírias", "erros", negando a heterogeneidade constitutiva da língua. Destacamos que, de todas as variedades, a culta é a que mais se aproxima da norma-padrão sendo muitas vezes confundida com esta. Ela é, portanto, a variedade que menos possui estigma. Designada dessa forma, a variedade culta é assim chamada, segundo os critérios do NURC, por estar mais próxima da intersecção dos estilos "do urbano, do letramento e dos estilos mais monitorados" (FARACO, 2008, p. 49), o que corresponde, no Brasil, a 15\% da população.

Em relação à língua portuguesa falada no Brasil, circulam discursos no senso comum como "isso não é português" ou "aquela pessoa não sabe falar português". A língua pode se adaptar às mais diversas situações comunicativas e as variedades são outras possiblidades, extremamente coerentes, do sistema gramatical. Instauram-se, assim, o preconceito e a intolerância linguísticos, pois, como diz Bagno (2010, p. 17 apud JUNQUEIRA et al., 2012, p. 246), "acusar alguém de não saber falar a sua própria língua materna é tão absurdo quanto acusar essa pessoa de não saber 'usar' corretamente a visão".

Segundo Leite (2008, p. 13), a intolerância linguística quase não é notada pela opinião pública e é "tão agressiva quanto outra qualquer, pois atinge o cerne das individualidades". Britto (2004) afirma algo semelhante ao dizer que "a língua é um dos lugares em que a ideologia é mascarada, é despercebida e, portanto, é violenta". Leite (op. cit., p.20) distingue intolerância e preconceito linguístico. Para ela, o preconceito se configura como "a idéia, a opinião ou o sentimento que pode conduzir à intolerância, à atitude de não admitir opinião divergente e, por isso, à atitude de reagir com violência ou agressividade a certas situações" (grifo da autora). 
O preconceitoé, portanto, uma opinião, um "não concordar", uma "não aceitação" da diferença, enquanto a intolerância se caracteriza por ser um comportamento, uma ação que evidencia a incapacidade "de o indivíduo conviver com a diversidade de conceitos, crenças e opiniões" (BOBBIO, 1992, p. 203-204 apud LEITE, ibid., p. 21). Em resumo, nas palavras da autora "A intolerância, [...] é ruidosa, explicita, porque, necessariamente, se manifesta por um discurso metalingüístico calcado em dicotomias, em contrários, como por exemplo, tradição $\mathrm{x}$ modernidade, saber x não-saber e outras congêneres" (LEITE, 2008, p. 24-25, grifos da autora).

A partir dessas discussões, observamos que o discurso purista sobre a linguagem, além de preconceituoso, é intolerante, ao fazer e propagar julgamentos sobre as variedades linguísticas, rotulandoas, pejorativamente, de "erradas", "não cultas", "populares". Esse preconceito também se dá com os sujeitos pouco "letrados", como mostram estudos sobre os letramentos.

Soares é autora brasileira que tem sido considerada uma das precursoras dos estudos sobre letramentos no país. Assume, já na década de 1980, que o acesso à escrita se trata de fenômeno complexo, interdisciplinar e relacionado à política:

[...] à natureza do processo de alfabetização, com suas facetas psicológica, psicolinguística, sociolinguística e linguística, é preciso acrescentar os fatores sociais, econômicos, culturais e políticos que o condicionam. Uma teoria coerente da alfabetização só será possível se a articulação e integração das várias facetas do processo forem contextualizadas social e culturalmente e iluminadas por uma postura política que resgate seu verdadeiro significado (SOARES, 1985, p. 23)

Assim, seu trabalho, à época, já se aproximava do que Street (2006) chama de "letramento ideológico": apontava para uma visão da escrita como atividade situada, social e culturalmente constituída. Soares entende o letramento (que ela chama à época de alfabetismo) como "um conceito complexo, pois engloba um amplo leque de conhecimentos, habilidades, técnicas, valores, usos sociais, funções, e varia histórica e espacialmente" (SOARES, 1995, p. 7). Colocandose de forma crítica aos que entendiam que as sociedades "letradas" possuíam uma superioridade sobre as sociedades orais (entendimento extensivo aos sujeitos participantes dessas sociedades) - ver Ong (1982) -, os estudos sobre "letramento ideológico" buscaram, entre outros 
aspectos, valorizar a produção cultural e a linguagem dos sujeitos à margem da sociedade escrita.Dentre a grande quantidade de estudos que versam sobre a temática, destacamos aqui obra organizada por Kleiman (1995), que coloca foco sobre as práticas de letramento de sujeitos pouco escolarizados e sobre os mitos sobre o letramento presente na mídia.

Este discurso de preconceito e intolerância em relação a determinados usos da linguagem está presente nos vídeos de Marcela Tavares, dos quais analisamos um neste trabalho. Propomos, aqui, analisar um trecho em que a atriz condena a expressão "sem concordância" dos falantes e dois em que condena grafias que não seguem convenções ortográficas. Transcrevemos o vídeo seguindo as normas para transcrição do projeto NURC, conforme quadro proposto por Koch (1992, p. 73), e o analisamos qualitativamente em seus aspectos verbais. ${ }^{1}$

\begin{tabular}{|c|c|c|}
\hline \multicolumn{3}{|c|}{ NORMAS PARA TRANSCRIÇÃO } \\
\hline OCORRÊECIAS & SINAIS & EXEMPLIFICACCAO \\
\hline Entoação enfática & maiúsculas & porque as pessoas reTÊM moeda \\
\hline $\begin{array}{l}\text { Alongamento de vogal ou consoante } \\
\text { (como s, r) }\end{array}$ & $\begin{array}{l}\text { :: podendo } \\
\text { aumentar para: : } \\
: \text { : ou mais }\end{array}$ & Ao emprestarem os... éh: : : ... o dinheiro \\
\hline Silabação & - & por motivo de tran-sa-ção \\
\hline Interrogação & $?$ & e o Banco... Central... certo? \\
\hline Qualquer pausa & $\ldots$ & $\begin{array}{l}\text { são três motivos... ou três razões... que } \\
\text { fazem com que se retenha moeda... } \\
\text { existe uma... retenção }\end{array}$ \\
\hline Comentários descritivos do transcritor & ((minúsculas)) & $(($ tossiu $))$ \\
\hline $\begin{array}{l}\text { Comentários que quebram a sequência } \\
\text { temática da exposição; desvio temático }\end{array}$ & ---- & $\begin{array}{l}\text {... a demanda de moeda -- vamos dar } \\
\text { essa notação -- demanda de moeda por } \\
\text { motivo }\end{array}$ \\
\hline $\begin{array}{l}\text { Citações literais, reproduções de } \\
\text { discurso direto ou leituras de textos, } \\
\text { durante a gravação }\end{array}$ & $" »$ & $\begin{array}{l}\text { Pedro Lima... ah escreve na ocasião... } \\
\text { "O cinema falado em língua estrangeira } \\
\text { não precisa de nenhuma baRREIra entre } \\
\text { nós"... }\end{array}$ \\
\hline
\end{tabular}

\section{Observações:}

1. Iniciais maiúsculas: não se usam em início de períodos, turnos e frases.

2. Fáticos: ah, éh, eh, ahn, ehn, uhn, tá (não por está: tá? 1 Extraídos de Castilho \& Preti (1986). A Linguagem Falada Culta na Cidade de São Paulo, vol. II Diálogos entre dois informantes. São Paulo. T. A. Queiroz/EDUSP, p. 9-10 apud Koch (1992, p. 73). Adaptado. 
Você está brava?)

3. Nomes de obras ou nomes comuns estrangeiros são grifados

4. Números: por extenso.

5. Não se indica o ponto de exclamação (frase exclamativa)

6. Não se anota o cadenciamento da frase.

7. Podem-se combinar sinais. Por exemplo: oh: : : ... (alongamento e pausa)

8. Não se utilizam sinais de pausa, típicos da língua escrita, como ponto-e-vírgula, ponto final, dois pontos, vírgula. As reticências marcam qualquer tipo de pausa.

Acrescentamos também algumas normas de criação própria para a transcrição do vídeo:

\begin{tabular}{|c|c|c|}
\hline$O C O R R E N C I A$ & SINAIS & EXEMPLIFIC СС \\
\hline $\begin{array}{l}\text { Discurso sobre aceitação social e } \\
\text { sucesso escolar: defende o purismo } \\
\text { argumentando sobre aceitação social e } \\
\text { bom desempenho escolar }\end{array}$ & $\underline{\text { sublinhado }}$ & $\begin{array}{l}\text { você acha que é maneiro falar... } \\
\text { escrever errado? cê acha que você } \\
\text { vai ter amigos? você acha que } \\
\text { você vai conseguir conquistar o } \\
\text { mundo falando errado? }\end{array}$ \\
\hline $\begin{array}{l}\text { O que está escrito na lousa atrás da } \\
\text { humorista }\end{array}$ & $<$ escrito $>$ & $\begin{array}{lllr}\text { PARE } & \text { DE } & \text { PEDIR } & \text { UMA } \\
\text { GRAMA... E E } & \text { UM GRAMA... } \\
\text { <UM grama }> & & \end{array}$ \\
\hline Discurso purista & negrito & $\begin{array}{l}\text { mas o correto é sempre usar } \\
\text { menos... menos é um advérbio e } \\
\text { não sofre alteração de gêneros }\end{array}$ \\
\hline
\end{tabular}

\section{TAVARES}

\section{O PRECONCEITO E A INTOLERÂNCIA NO VÍDEO DE MARCELA}

A série Não sejA burro! é composta por quatorze vídeos, desconsiderando-se os "especiais". O primeiro vídeo da série foi lançado em 11 de janeiro de 2016 com 6 minutos e 27 segundos de duração, no canal do YouTube da humorista. Em agosto de 2017, este vídeo contava com 1.470 .952

visualizações, 105.458 curtidas nesta rede online e, em março de 2018, os números eram 1.937.334 visualizações e 140 mil curtidas.

Marcela Tavares aparece em seus vídeos usando óculos, com os cabelos presos, com frutas na blusa simulando seios grandes e na frente de uma lousa branca, representando uma professora que ministra uma aula online de língua portuguesa, aos gritos. Segundo a humorista (TAVARES, 2016), sua proposta é ensinar a língua "de uma forma exótica". 
Observamos que, na forma verbal "seja" do título Não seja burro!, o $<$ a $>$ aparece em maiúsculo $(<\mathrm{A}>$ ), indicando destaque. Uma interpretação para esse destaque no verbo ser é que Marcela Tavares pretende indicar qual a maneira "correta" de conjugar esse verbo, tomando "seje" como a forma "errada".

Destacamos, ainda, que no que concerne ao conteúdo do título, tendo em vista o assunto de que trata o vídeo, Marcela Tavares é preconceituosa ao xingar seu interlocutor de "burro" porque ele não emprega a variedade linguística que ela julga ser correta. O posicionamento adotado pela atriz em sua série de vídeos demonstra que ela se admite detentor a de um conhecimento que seu interlocutor não possui, assim como considera superior a variedade de língua que usa, julgando, então, que deve "ensinar o português correto" aos espectadores que passariam de uma condição de "burros" a "não burros".

Nesta seção, comentamos três trechos selecionados e transcritos do primeiro vídeo da série. Primeiramente, comentamos um trecho em que Marcela Tavares condena a falta de concordância e, a seguir, analisamos outros dois trechos em que a atriz ridiculariza questões de ortografia.

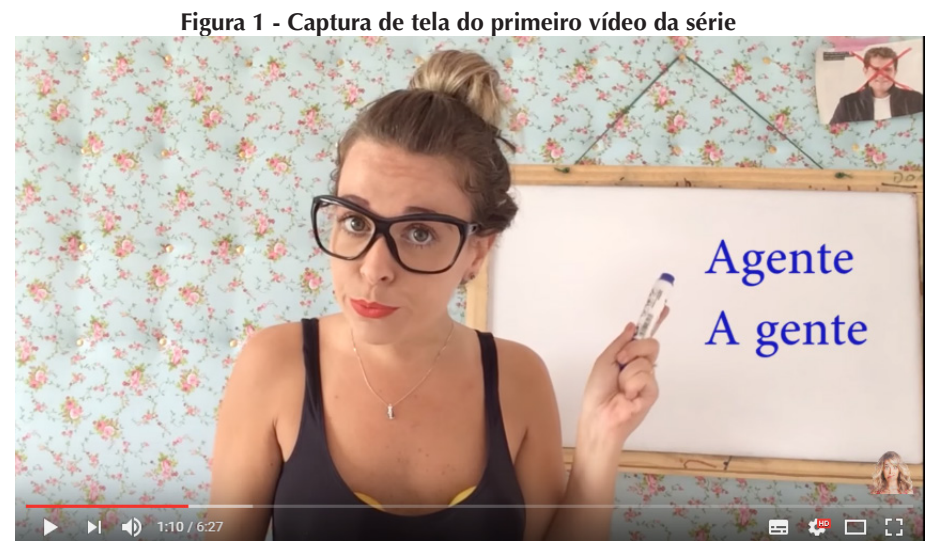

Fonte: https://www.youtube.com/watch?v=Uy_0zzOdgXona

Nesse trecho, a humorista diz que é feio não colocar plural. Acrescenta que é necessário escrever certo, o que pressupõe que não colocar plural é errado. Além disso, a atriz diz que "às vezes tu fala de sacanagem" como se esse fenômeno fosse sempre intencional, uma 


\section{Quadro 1 - Trecho 1 - Tempo: 05 ' 45 ,}

mas agora com as redes sociais também as pessoas usam muita gíria... muita abreviação... o que eu num acho errado... não... só que na hora da prova você vai se lascar porque você num pode fazer isso... então tu tem que saber escrever certo... e tu...pelo amor de Deus... coloca plural em tudo... coloca... às vezes tu fala de sacanagem igual eu tô fazendo aqui agora... mas é feio... num colocar plural é feio a num ser que você queira ser um cantor de funk... aí tá liberado num saber plural...

brincadeira. A atriz não reflete sobre como isso, que ela chama de "erro", ocorre, e tampouco esclarece o porquê de, sendo um "erro", é, ainda assim, compreensível. Isso deixa claro que se trata de uma avaliação subjetiva da humorista, sem embasamento científico.

Sabe-se que, na norma-padrão do português brasileiro e nas variedades cultas, a marcação de plural é redundante, isto é, ela é marcada em diversos elementos da sentença, o que justifica que haja uma tendência em sua não-marcação (TARALLO, 1985). Por economia, o falante pode marcar o plural no termo que introduz a ideia (tema) sobre a qual quer falar e, a seguir, não trazer mais marcações, nem no sintagma nominal nem no verbal, pois uma marca já é suficiente para que a pluralidade seja compreendida. Assim, aquilo que a humorista trata como "erro", uso "feio" da língua, é fator de variação linguística muito acentuado no uso brasileiro, sendo que se encontra inclusive na linguagem oral de falantes de norma culta, como atestam estudos desenvolvidos no interior do Projeto NURC (PRETI, 1997).

Além do aspecto valorativo que manifesta em relação à falta de concordância, apresentando preconceito linguístico, a Youtuber relaciona esse uso linguístico a uma manifestação cultural, o funk: "não saber plural" só está permitido aos cantores de funk (uma paráfrase dessa sua fala poderia ser: "ser ignorante" só cabe aos funkeiros. Observamos que, além de manifestar preconceito linguístico e intolerância, ela também condena a cultura do funk. Ao ter feito uma valoração negativa do não emprego do plural e associá-lo a esse gênero musical, a humorista atribui também ele essa característica depreciativa, desprezando, assim, conjuntamente, língua e expressão cultural, confirmando a relação já citada na seção anterior entre preconceito linguístico e preconceito social: um reafirma o outro. Língua e falante estão imbricados necessariamente, no conjunto da vida social.

A seguir, vejamos outros trechos do vídeo em pauta, em que a humorista se manifesta sobre erros ortográficos. 
Figura 2 - Captura de tela do primeiro vídeo da série "Não seja burro"

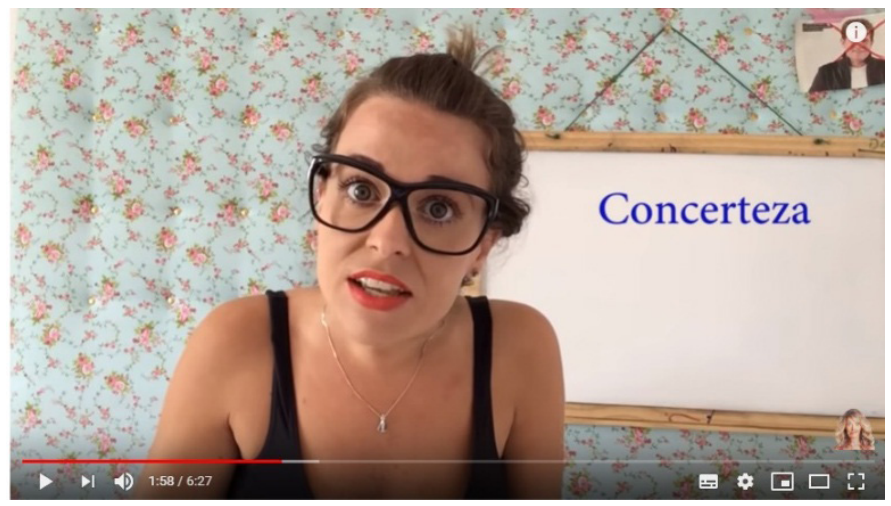

Fonte: https://www.youtube.com/watch?v=Uy_0zzOdgXo

\section{Quadro 2 - Trecho 2 - Tempo: 01'57',}

com certeza junto.... quem foi o desocupado que começou a usar isso... né? porque num sei onde que com certeza é com n e junto... não... É COM ... COM CERTEZA... separado com m...

Quadro 2 - Trecho 2 - Tempo: 01'57". Fonte: <https://www.youtube.com/watch?v=Uy_0zzOdgXo>

Marcela Tavares questiona "quem foi o desocupado que começou a usar isso" ao se referir à forma escrita concerteza. Assim, segundo ela, alguém ocioso, sem ocupação, começou a adotar essa grafia para "com certeza". A atriz acrescenta que não sabe onde "com certeza é com n e junto". Depreendemos dessa sentença que, segundo Tavares, se concerteza "não está em nenhum lugar", não existe.

É importante destacar que a ortografia é uma convenção da cultura escrita, um conjunto de regras que prevê uma grafia padrão para as palavras de uma língua, sendo que há diversas grafias diferentes para um mesmo som.

Contudo, não se adequar a essa convenção não é um ato "sem sentido" ou "absurdo", pois a escolha gráfica que o falante faz tem sistematicidade e lógica, considerando as práticas de escrita a que teve acesso. As escolhas, mesmo que em desacordo com as regras ortográficas, são tentativas de acerto. Seguir as regras está intimamente ligado à escolarização e à leitura. Como dizem Marquardt e Busse (2015, p. 191): "São os meios escolares que oferecem o que a maioria dos estudantes brasileiros não dispõe em seus lares: a possibilidade da leitura, que implicará no domínio da língua escrita" e, nas palavras de Bortoni-Ricardo (2013, p. 55 apud Marquardt e Busse, op. cit.), 
"O domínio da ortografia é lento e requer muito contato com a modalidade escrita da língua. Dominar bem as regras de ortografia é um trabalho para toda a trajetória escolar, e quem sabe, para toda a vida do indivíduo".

Desse modo, ao analisarmos concerteza, verificamos que a opção por juntar "com" e "certeza" se deu, provavelmente, porque o falante ouve a expressão "com certeza" num contínuo e não como duas palavras. Acrescentamos que grafar $<\mathrm{n}>$ anteposto à consoante [s], grafada $<\mathrm{c}>$, demonstra pleno domínio da regra ortográfica segundo a qual apenas antes de $\langle\mathrm{p}>$ e $<\mathrm{b}>$ se grafa $<\mathrm{m}>$. Dessa forma, há sistematicidade e lógica no uso linguístico que é um erro ortográfico. O sujeito que erra ortografia está tentando acertar.

Figura 3 - Captura de tela do primeiro vídeo da série "Não seja burro"

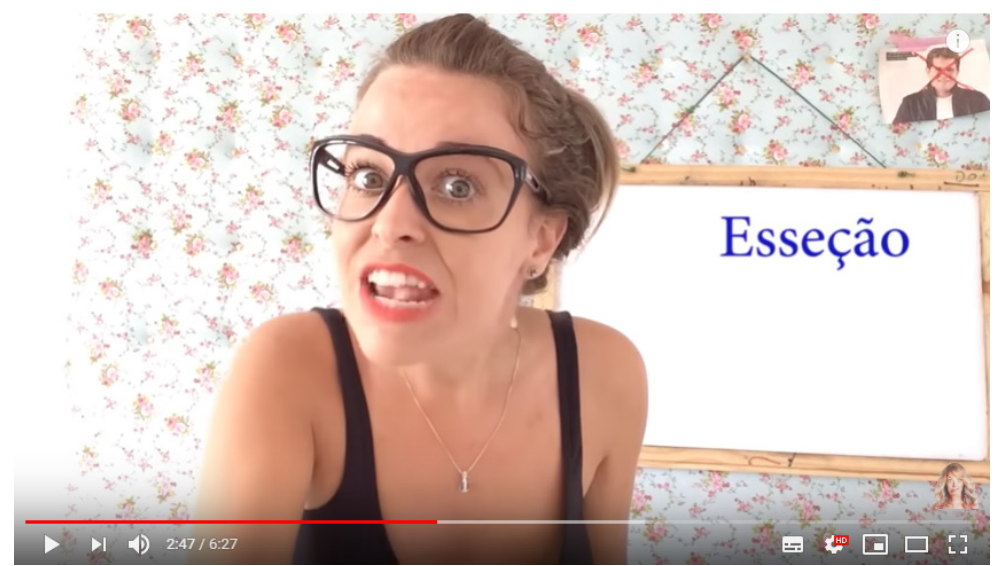

Fonte: https://www.youtube.com/watch?v=Uy_0zzOdgXo1973,

\section{Quadro 3 - Trecho 3 - Tempo: 02'37'"}

exceção não se escreve com dois $\mathbf{s}$... por que que as pessoas fazem isso então? inventa... inventa... "ah eu acho que é com dois s"... mas num é... não é... e olha só... coloca uma coisa na tua cabeça... e fica falando isso durante uma semana até impregnar aqui... ((bate na própria cabeça)) X... C... C... X... C... Ç... X... C... C... X... C... С ((voz em falsete, acelerado)) GRAVA... GRAVA... decora isso... faz uma música com isso pra você aprender a escrever exceção...

Quadro 3 - Trecho 3 - Tempo: 02'37". Fonte: https://www.youtube.com/watch?v=Uy_0zzOdgXo.

Marcela Tavares, falando sobre a forma esseção, diz que "não se escreve com dois s" e pergunta por que, então, as pessoas escrevem assim. Em resposta à sua própria pergunta, diz que quem usa essa

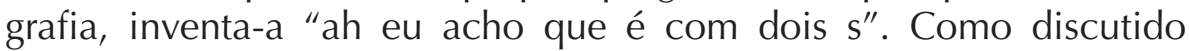


anteriormente, o indivíduo, ao ter dúvidas sobre qual grafia empregar para determinado som, elege uma dentre as possibilidades que seu contato com a escrita Ihe permite inferir. Segundo Marquardt e Busse (2015, p. 191), não seguir as regras ortográficas não demonstra que "o aprendiz deixou de se apropriar do sistema de compreensão da escrita, porém, que está elegendo possibilidades de uso da língua".

No caso de esseção, há várias possiblidades de grafia para o som [s]. Quando isso ocorre, temos o fenômeno da concorrência, pois a escolha da letra apropriada para representar certo fonema depende não de aspectos fonológicos, mas da etimologia ou de aspectos morfológicos. Encontram-se nessa categoria o uso de $s$ ou $z$ entre vogais, o uso de ss ou ç diante de a, $o$ e u, o uso de g ou j diante de e e i, o uso de $x$ ou ch em várias palavras. (NOBILE; BARRERA, 2009, p. 41 - grifos das autoras).

Salientamos que o som [s] tem, em português, nove transcrições diferentes. É o que aponta Beline (2008, p. 142) "Por incrível que pareça, é isso o que temos em: som, nosso, centro, preço, exceto, sintaxe, voz, crescer e cresça". Assim, ao escrever esseção, o indivíduo reflete profundamente sobre a língua, escolhendo uma possibilidade dentre nove. Uma tarefa bastante difícil, ao contrário do que supõe a humorista.

\section{CONSIDERAÇÕES FINAIS}

A partir das discussões feitas, pudemos observar que, no vídeo de Marcela Tavares, há a reprodução de um discurso purista sobre a linguagem que acarreta preconceito linguístico e social. Algumas observações podem ser feitas sobre o vídeo em questão e que podem motivar futuros trabalhos na área.

Em primeiro lugar, entendemos que o discurso da humorista sobre o erro chama atenção porque rotula de "erro" algo que é completamente "lógico" considerando o sistema linguístico oral e o padrão escrito do português brasileiro. Inclusive, elege a concordância como tema para ilustrar o "erro" - deve haver uma razão para fazer isso. Seria a concordância um divisor de águas entre os mais e menos escolarizados, portanto, um lugar bom para praticar o preconceito linguístico e a intolerância social?

Outro aspecto que nos chama atenção é que o preconceito 
linguístico e a intolerância, dos quais temos tantos estudos no país no campo da Sociolinguística, atinge questões de acesso a práticas letradas. Isso nos parece indício de que um estudo que tematize as práticas linguísticas e seus desdobramentos políticos e sociais deva ser interdisciplinar para tentar dar conta da complexidade da questão que é a relação entre sujeito (identidade) e linguagem.

\section{REFERÊNCIAS BIBLIOGRÁFICAS}

BAGNO, M. Preconceito linguístico: o que é, como se faz. 1 ed. São Paulo: Edições Loyola, 1999

BELINE, R. A variação linguística. In: FIORIN, J. L (Org.). Introdução à Linguística. São Paulo: Contexto, 2008. p. 121-140.

BOURDIEU, P. Economia das Trocas Linguísticas: o que falar quer dizer. Tradução de Sergio Miceli et al. São Paulo: Editora da Universidade de São Paulo, 1996.

BRITTO, L. P. L. Língua e ideologia - A reprodução do preconceito. In: BAGNO, M. (Org.) Linguística da norma. São Paulo: Edições Loyola, 2004, p. 135-154.

FARACO, C. A. Norma culta brasileira: desatando alguns nós. 1 ed. São Paulo: Parábola Editorial, 2008.

GUIMARÃES, L. Só 14\% dos adultos no Brasil tinham ensino superior em 2015, nota OCDE. Econômico Valor, 15 set. 2016. Disponível em

http://www.valor.com.br/brasil/4710581/so-14-dos-adultos-no-brasil-tinhamensinosuperior-em-2015-nota-ocde. Acesso em: 4 jul. 2017.

GUY, G.R.; ZILLES, A.M.S. O ensino da língua materna: uma perspectiva sociolinguística. Calidoscópio, v. 4, n. 1, p. 39-50, jan./abr. 2006.

JUNQUEIRA, M. E. B.; SOUZA, A. B.; SILVA, G; D.; SILVA, L. F.; ALMEIDA, V. A. S.

O preconceito linguístico na mídia televisiva. Cadernos do CNLF - Anais do XVI CNLF, Rio de Janeiro: CiFEFiL, vol. XVI, nº 04, 2012. Disponível em: http://www.filologia.org. br/xvi_cnlf/tomo_3/212.pdf. Acesso em: 3 set. 2017.

KLEIMAN, A. (Org.) Os significados do letramento: uma nova perspectiva sobre a prática social da escrita. Campinas: Mercado de Letras, 1995.

LABOV, W. Padrões sociolinguísticos. Tradução de Marcos Bagno; Maria Marta Pereira Scherre; Caroline Rodrigues Cardoso. São Paulo: Parábola Editorial, 2008.

LEITE, M. Q. Preconceito e intolerância na linguagem. 1 ed. São Paulo: Editora Contexto, 2008.

MARCOS Bagno: a língua como instrumento de poder. Entrevista para a 9a Bienal da

UNE. UNE, nov. 2014. Disponível em https://www.une.org.br/2014/11/marcos-bagnoalingua-como-instrumento-de-poder/. Acesso em: 04 mar. 2017.

MARQUARDT, V. C.; BUSSE, Sanimar. Um estudo dos erros ortográficos em produções escritas de alunos do $9^{\circ}$ ano do ensino fundamental. Revista Educação e Linguagens, 
Campo Mourão, v. 4, n. 6, jan./jun. 2015.

NÃO SejA Burro!. Realização de Marcela Tavares. Intérpretes: Marcela Tavares. S. I.:

Marcela Tavares, 2016. (6 min. 27 seg.), son., color. Série Não SejA Burro!. Disponível em:

https://www.youtube.com/watch?v=Uy_0zzOdgXo\&t=104s. Acesso em: 10 abr. 2017.

NEVES, M. H. M. A Gramática do Português Revelada em Textos. 1 ed. São Paulo: Editora UNESP, 2018.

NOBILE, G. G.; BARRERA, S. D. Análise de erros ortográficos em alunos do ensino público

fundamental que apresentam dificuldades na escrita. Psicologia em Revista, Belo Horizonte, v. 15, n. 2, p. 36-55, ago. 2009. Disponível em: http://pepsic.bvsalud.org/pdf/ per/v15n2/v15n2a04.pdf Acesso em: 13 nov. 2017.

ONG, W. J. Orality and literacy: the technologizing of the world. London: Methuen, 1982.

PRETI, D. (org.) O discurso oral culto. 1 ed. São Paulo: Universidade de São Paulo, 1997.

SANTOS, L. B. Não sejA burro! o preconceito linguístico e a intolerância no discurso de Marcela Tavares. 2017. 62 f. Trabalho de Conclusão de Curso (Bacharelado) - Faculdade de Ciências e Letras (UNESP), Araraquara, 2017.

SOARES, M. As muitas facetas da alfabetização. Cadernos de pesquisa. Fundação Carlos Chagas, São Paulo, n. 52, p. 19-24, fev. 1985.

. Linguagem e escola: uma perspectiva social. 1 ed. São Paulo: Ática, 1986.

. Língua escrita, sociedade e cultura: relações, dimensões e perspectivas. Revista brasileira de educação, n. 0, set.-nov. 1995.

STREET, B. Perspectivas interculturais sobre o letramento. Filologia e Linguística Portuguesa, n. 8, p. 465-488, 2006.

TARALLO, F. A pesquisa sociolinguística. 1 ed. São Paulo: Ática, 1985.

WEINREICH, U.; LABOV, W.; HERZOG, M. Fundamentos empíricos para uma teoria da mudança linguística. Tradução de Marcos Bagno. 1 ed. São Paulo: Parábola Editorial, 2006.

Recebido em: 03/06/2019

Aceite em: 16/06/2019 